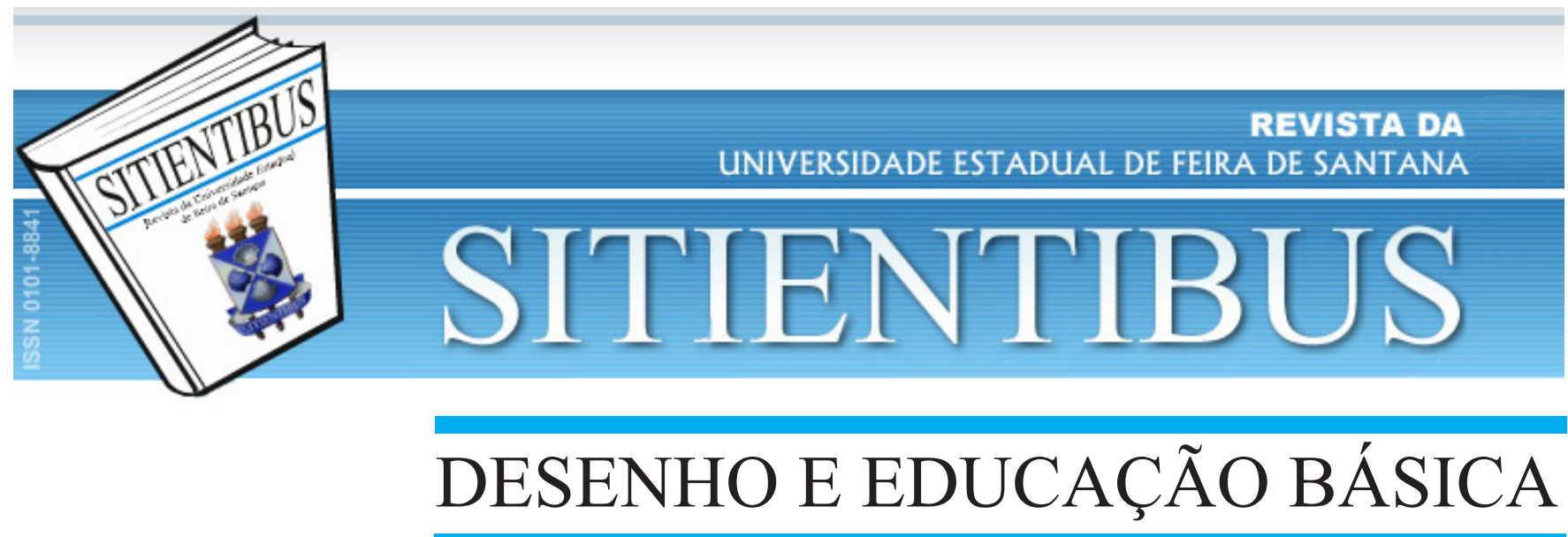

ARTIGO

\title{
REPRESENTAÇÃO SOCIAL DO CORPO: IMPLICAÇÕES DA IMAGEMNOS DESENHOS INFANTIS
}

\section{SOCIAL REPRESENTATION OF BODY: IMPLICATIONS OF IMAGE IN CHILDREN'S DRAWINGS}

FÁtIMA SUELY BARBosa dA SiLVA CORREIA

Mestre em Desenho, Cultura e Interatividade (UEFS). E-mail: fatimasuely@hotmail.com

LILIAN MIRANDA BASTOS PACHECO

Doutora em Educação, Professora Adjunta do Departamento de Educação (DEDU/UEFS). E-mail: lilianmbp01@gmail.com

\section{RESUMO}

O objetivo deste artigo se inscreve na perspectiva de discutir o desenho do corpo humano produzido por crianças à luz da teoria da Representação Social ancorada nos estatutos teóricos de Moscovici (2003) e,dos estudos de Gomes (1996) e Derdyk (2003) acerca do desenho.O que se pretende traçar, ainda que de forma preliminar, é uma conexão entre os desenhos infantis sobre a figura humana e os aspectos que se revelam para além da composição visual apresentada nestes grafismos. Destacam-se alusão aos heróis dos desenhos animados e as relações de gênero.

Palavras-chave: Corpo; representação social; desenho da figura humana.

\section{ABSTRACT}

This article falls within the context of discussing the design of the human body produced by children in the light of the theory of Social Representation theory anchored in the statutes of Moscovici (2003) and studies of Gomes (1996) and Derdyk (2003) on the design. What we intend to draw, albeit in simplified form, is a connection between children's drawings on the human figure and the aspects that reveal beyond visual composition shown in these graphics. Among them allude to cartoon heroes and gender relations.

Keywords: Body; social representation; human figure drawing.

\section{INTRODUÇÃO}

Tomando por base a assertiva de que o conceito de Representação Social possui uma amplitude cuja polissemia de significados engendra múltiplos aspectos a serem considerados, delineia-se, neste trabalho, a necessidade de apresentar alguns destes sentidos a fim de que, no seu decorrer,seja possível apresentar, no contexto do desenho infantil, as nuances que se associam à linguagem gráfica visual e sua capacidade de representar um objeto ou o corpo humano.
Assentada sobre o seu significado mais amplo, a representação, designada dentro de uma perspectiva lato sensu, está relacionada ao sentido paradoxal da presentificação de uma ausência. Acerca deste, Laclau (apud Mendonça, 2004, p.82) destaca que:

A representação é o processo no qual o outro - o representante - "substitui" e ao mesmo tempo "encarna" o representado. As condições de uma perfeita representação parecem ser dadas quando a representação é um processo direto de transmissão da vontade do representado quando 
o ato de representação é totalmente transparente em relação a esta vontade. Isto pressupõeque a vontade esteja plenamente constituída e que o papel do representante se esgote nesta função de intermediação. Desta forma, a opacidade inerente a toda substituição e encarnação devem ser reduzidas a um mínimo: o corpo em que a encarnação tem lugar deveser quase invisível.

Ao tomarmos como base o aspecto anunciado da invisibilidade, é possível indicar pontos de contraste deste aspecto na obra de René Magritte (1898-1967), pintor belga, participante da vanguarda estética do alto modernismo, cujas imagens insólitas buscam contestar o enunciado, ao apresentar uma relação não linear entre o quadro e seu título, objetivando "vencer o automatismo do pensamento". (ALMEIDA, 2006, p. 91). A originalidade da obra de Magritte destaca-se. $O$ duplo representante e representado aparecem como um continum de configurações estéticas, "contrariam o senso comum ao destruir certos pontos de vista dogmáticos sobre o mundo físico e mental" (ARBEX, 2007, p.148).

Nesta ótica a arte erudita, com alta expressividade e linguagem universal, pode ser representada, neste artigo, através das pinturas de Magritte. Estaspotencializam o olhar num convite a desvendar enigmas. Nesta direção, destacamse os aspectos da representação e da desconstrução desta contidos na obra magrittiana. Tais características podem ser observadas em alguns quadros como, O terapeuta (1941) e Os amantes (1928). Em ambos os títulos/enunciados levam o espectador a contestar "todo laço simples e aparente de relação entre visível e enunciável (título ou elemento verbal no espaço pictórico) descortinando uma não-relação por trás da representação" (ALMEIDA, 2006, p. 91).

Ao trazer para o campo das artes plásticas este emaranhado de ligações entre o visível e o enunciado, Magritte expõe fraturas imperceptíveis entre o representante e o representado, demonstrando choques, aproximações e distanciamentos entre as condições representativas e a representação pictórica e linguística. Estas aproximações provocam o estranhamento e estabelecimento de complexos jogos de sentido.

É importante assinalar a função de intermediação sob a qual a representação se assenta, redefinindo uma relação dialética sujeito-objeto nos fenômenos das relações sociais.Para ilustrar tal categoria podemos destacar a fotografia enquanto efeito de presença ao anunciar uma imagem, um recorte arbitrário de um mundo sensível que passa a ser, no momento da representação fotográfica, restrito no espaço e no tempo.

Um retrato pode ser examinado minuciosamente, com uma insistência com que não ousaríamos olhar o próprio retratado.É como estar do outro lado do espelho, observando sem risco de ser observado também - um monólogo, sem implicações de outro olhar para dialogar. Esta condição de espectador torna a observação da vida através da fotografia totalmente diversa da observação direta da própria vida. (Kubrusly, 2003, p. 57)
Considerando o sentido polissêmico do termo representação, Rangel (1998, p. 74) discorre acerca da fragilidade e dispersão paradigmática deste conceito, ao tempo em que enfatizaque o "leque de elementos que se apresentam na compreensão do fenômeno representativo ofereça a possibilidade de ampliar os horizontes de suas aproximações". Neste sentido é importante considerar alguns elementos apresentados nos estudos fundamentados em Moscovici (2003) como, por exemplo a compreensão de que "... as representações individuais e sociais fazem com que o mundo seja o que pensamos que ele é ou deva ser." (Rangel, 1998, p.75)

Esse princípio corrobora com a compreensão na qual se determina que as representações sociais se constituem num conjunto de elementos interconectados de representação da realidade. Deste entendimento, pode-se inferir que o desenho infantil, enquanto linguagem gráfica que se constrói no plano social, é orientado pelas condutas e comportamentos dos indivíduos, se constituindo num dos meios pelos quais "formam-se, conformam-se e veiculam-se as representações". (Rangel, p. 76, 1998)

\section{Desenho: Linguagem gráfica visual}

Outro aspecto a ser evidenciado é odesenho enquanto linguagem gráfica visual. Para Gomes (1996) a busca pelas diversas significações, literais ou não, da palavra desenho e de outros vocábulos relacionados é imprescindível. O passeio pela semântica faz revelar algumas relações entre os meios de produção, a organização econômica e a língua ou signos verbais das diversas civilizações. Este percurso é feito para que seja possível ampliar a compreensão de sua origem e o estabelecimento de concatenações que tragam à tona um entendimento do termo e da ação de desenhar, envolvendonovos modos e usos deste. Como assevera o autoro desenho pode ser concebido por meio de:

\section{Uma visão esclarecedora de uma das formas de expressão humana que melhor permite a representação (grifos nossos) de coisasconcretas e abstratas que compõem o mundo natural ou artificial em que vivemos. (Gomes, 1996p. 13)}

Torna-se necessário assinalar que foi tomadoporbase, neste estudo, a concepção do desenho como representação cujo sentido assume, de acordo com o contexto, o significado de "ordem e arranjo" (op cit., 29) "projeto, desígnio, intentos do inimigo". (op cit., 30). "representar, traçar, riscar, representar de qualquer forma visível, dar a linha, dar a ideia de, descrever..." (op. cit., 32). Esta análise documental objetiva re-construir os territórios e limites da linguagem do desenho como ponto fundamental "para a compreensão de aspectos da cultura material e, em particular, da influência desta sobre a cultura das ideias e do comportamento de um povo." (Gomes, 1996, p. 15)

Tais implicações codificam a reinterpretação do mundo imagético, nesta análise do desenho como representação, 
considerando-o um reflexo das circunstâncias materiais de uma sociedade. Assim, na perspectiva do desenho enquanto linguagem e como forma de apreensão do mundo e do conhecimento, este é focalizado como veículo de representações sociais, que ao mesmo tempo desvela valores, preferências, afetos, por outro lado, encobre contradições refletindo "modelos de minorias hegemônicas, ao invés da realidade da vida popular." (Rangel, 1998, p. 78)

Para ilustrar o caráter ideológico e dialético das representações visuais, apresentam-se a seguir quatro desenhos produzidos por crianças (duas do sexo masculino e duas do sexo feminino), estudantes do 3 o ano de uma escola rural da Micro-Região de Feira de Santana, cuja faixa etária situa-se entre os 8 a 10 anos. Estes desenhos são representações da figura humana produzidos como atividade artística livre na qual os alunos foram orientados apenas sob o tema a ser considerado em suas produções. Foi solicitado, durante a aula, que os alunos desenhassem uma figura humana.

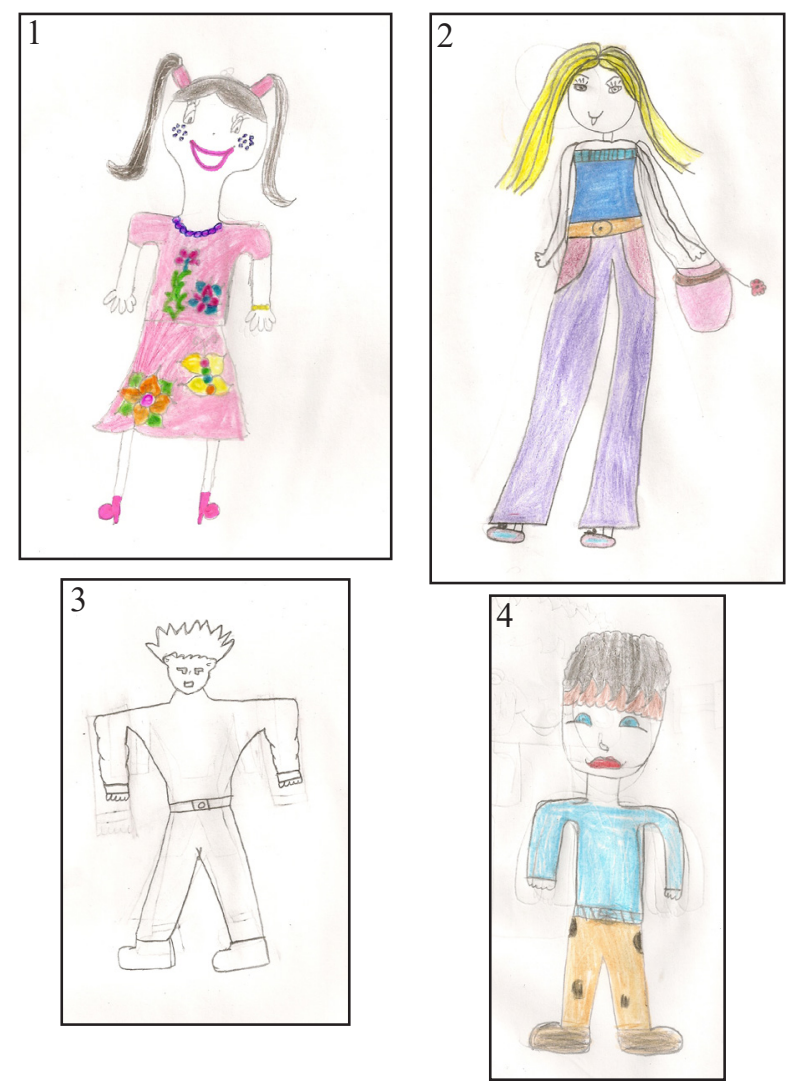

Figuras 1, 2, 3 e 4: Desenhos da figura humana produzidos pelos alunos.

\section{A representação social do corpo através dos desenhos de escolares: análises}

Dentre os vários tipos e temas abordados pelas crianças no desenho, por elas produzidos espontaneamente, um dos mais frequentemente realizados é o da figura humana. Koppitz (apud Wechesler 2002, p. 29) realça que "Outros temas fazem parte dos desenhos livres infantis, porém em frequência bem menor que o da figura humana".
Derdyk (2003) convida-nos a uma importante discussão: a representação visual do corpo por crianças como um "convite para flagrarmos o processo de construção da visão de mundo da criança." (Derdyk, 2003, p. 104). Acerca deste, ela assevera:

\begin{abstract}
...O corpo é a testemunha de nossa existência, documento vivo. A figura é o que a gente vê, compartilhando com a imagem e a representação o significado daquilo que o corpo emana, sendo no mundo. A figura representa a imagem do corpo ao outro, e nessa comunicação silenciosa reinam as personas, as máscaras sociais, a figura que a gente constrói de si para o mundo. O corpo é efêmero, a figura é eterna ao edificar sua imagem e sua representação. (Derdyk, 2003, p. 31)
\end{abstract}

Nesta direção, as análises aqui explanadas objetivam identificar, nos elementos constitutivos destes desenhos, uma rede de sentidos que, a priori, podem representar as visões deste grupo e do segmento social do qual fazem parte. Retomase o conceito de representação apresentado em Moscovici (2003) que re-direciona este aporte, considerando-o um fenômeno social que agrega ao pensamento um sentido natural e autônomo.

\begin{abstract}
Pessoas e grupos criam representações no decurso da comunicaçãoe da cooperação. Representações, obviamente, não são criadas por um indivíduo isoladamente. Uma vez criadas, contudo, elas adquirem uma vida própria, circulam, se encontram, se atraem e se repelem e dão oportunidade ao nascimento de novas representações, enquanto velhas representações morrem. Como consequência disso, para se compreender e explicar uma representação, é necessário começar com aquela, ou aquelas, das quais nasceu. (...) sendo compartilhada por todos e reforçada pela tradição, ela constitui uma realidade sui generis. Quanto mais sua origem é esquecida e sua natureza convencional é ignorada, mais fossilizada ela se torna. (Moscovici, 2003, p. 41)
\end{abstract}

Ao observar as quatro figuras apresentadas anteriormente énotório a apresentação de elementos que trazem a marca de uma sociedade hegemônica: cabelos lisos e claros para as figuras femininas, cútis clara em todos os desenhos, porte físico atlético nos desenhos masculinos e semelhanças estéticas em ambos com os cânones do corpo humano aceitos pela sociedade vigente e referendados nos diversos veículos de comunicação de massa, dentre os quais, os canais de televisão.

Para nos aproximarmos das conexões existentes entre a cultura e seus padrões criados não de forma autóctone, mas a partir da difusão e empréstimos tomados a outros sistemas culturais e o desenho da figura humana em sua contemporaneidade, torna-se importante a análise do entendimento do corpo nas diferentes fases e contextos da história humana a partir de uma visão filosófica. Esta reflexão tem como objetivo primordial observar de que forma o corpo foi compreendido, especialmente, a partir de duas posições: a idealista e a materialista. 
Explicar o homem, não como uma unidade integral, mas como um composto de duas partes diferentes: corpo e alma, sempre foi uma tendência entre os filósofos. Já em Platão observa-se um movimento nesta direção, no qual a alma deve exercer um domínio sobre o corpo, por ele denominado de alma inferior. No entanto este posicionamento pode parecer contraditório se examinarmos a questão sob a perspectiva de que os gregos sempre se preocuparam com o corpo.

Platão valorizava, intensivamente, os estímulos ao corpo através da educação física. Para ele, tais exercícios concorriam para que fosse alcançada uma saúde perfeita, que permitisse a alma se concentrar na contemplação das idéias. Sua célebre frase "Corpo são em mente sã" ratifica este pensamento.

O nu encarna valores espirituais das divindades, como a medida, o equilíbrio, a modéstia e a proporção. O belo designa uma qualidade rítmica das coisas (...). A beleza, no entanto, não está no corpo ou no trabalho do artista, uma vez que o belo grego não é uma categoria artística; antes supõe um discurso filosófico. (MATESCO, 2009, p.15)

Até o século XIII, no período que se constitui do final da Antiguidade até a Alta Idade Média, observa-se a influência do pensamento de Platão, embora reconfigurado a partir das revelações cristãs que apregoam o corpo como sinal de pecado e degradação. "A figura humana é caracterizada por uma gramática religiosa e simbólica, excluindo a representação do real". (Derdyk, 2003, p. 45).

O Renascimento e a Idade Moderna, rompendo com este paradigma, refutam o status quo instituído acerca do entendimento sobre a realidade corpórea, promovendo a dessacralização do corpo. Destacam-se, nesta época, pensadores de todas as áreas entre os quais: Bacon, Descartes, Galileu e o pintor Rembrandt que ilustra, em uma de suas obras, esta "profanação" do corpo no célebre quadro A lição de anatomiano qual representa este novo olhar do homem sobre o mundo numa perspectiva dos anatomistas que desafiam a proibição da Igreja de dissecar cadáveres.

O pensamento renascentista reabilita o humano, o corpo espelha e habita a esfera do real, objetivando uma identidade corporal material e estética. Neste eixo, Aranha (1986, p. 345) afirma que:

Tal posicionamento determina uma nova visão do corpo: o corpo-objeto, associado à idéia mecanicista do homem-máquina, É Descartes que afirma: "Deus fabricou nosso corpo como máquina e quis que ele funcionasse como instrumento universal, operando sempre da mesma maneira, segundo suas próprias leis". Com isso Descartes torna o corpo autônomo, alheio ao homem.

A tentativa de superar a dicotomia corpo-espírito, consciência-objeto, homem-mundo, buscando fugir às polarizações que demonstrem uma ou outra dimensão humana, tem sido evidenciada na contemporaneidade através da busca do entendimento da coexistência e totalidade de ambos no ser humano.

O corpo humano jamais poderá ser uma coisa entre outras coisas e, nesse sentido, a relação do homem com o seu corpo nunca será objetiva, mas carregada de valores. O corpo nunca é dado ao homem como mera anatomia: o corpo é a expressão dos valores sexuais, amorosos, estéticos, éticos, ligados bem de perto às características da civilização a que pertencemos (ARANHA, 1986, p. 349).

Com efeito, esta relação corpo-homem é, carregada de valores (ARANHA, 1986). Ela sustenta-se nas relações culturais estabelecidas sob os quais nosso modo de ver o mundo assenta-se, apresentando-se sob uma infinidade de formas e características que são produtos dos condicionantes culturais da civilização que nos concerne.

Considerando esta perspectiva observam-se nos desenhos infantis das figuras masculinas (figuras 3 e 4) algunstraços, como por exemplo, os desenhos dos cabelos que referendam, os heróis de desenhos animados atuais. Fato este que indica a expressiva repercussão dos símbolos, significados e imagens nas representações desenhísticas das crianças e que nos leva a considerar pertinente o realce dado por Rangel (1998) à ideologia como um dos fatores da representação com "poder de influência no entorno e no interior do fenômeno representativo." (Rangel, 1998, p. 77)

As idéias incorporadas ao que se representa não são todas aquelas que circulam na sociedade, mas apenas as da classe que, num certo momento histórico, é dominante. Essas questões teóricas aplicam-se ao desvelamentoda formação e representação do processo avaliativo, no qual permanecem os reflexos da seletividade e elitização escolar e social. (Rangel, 1998, p. 78)

Sobre a influência dos desenhos animados o público infantil, faz refletir em seu repertório cultural no qual a linguagem gráfica do desenho está incluída, conceitos, aprendizagens, informações que são processadas e incorporadas ao seu modo de vida e pensamento.

O desenho animado, como ueroutraproduçãocultural (relações com pai, mãe, irmãos, escola, professor, colega, entre outros), faz parte do contexto e é fonte de informação para ascrianças, mas a maneira como elas (as crianças) internalizam os conceitos veiculados e os aplicam em ações é algo que não se pode prever a priori, só podendo ser entendida através de relações estabelecidas com os vários aspectos culturais com os quais elas (as crianças) não só se confrontam, como incorporam, negam ou reconfiguram pela linguagem. (Bortoletto, 2008, p.85)

Outra perspectiva acerca do desenho animado ancora-se na relação deste com a concepção de herói que atravessa o contexto infantil. Para Salgado (2005) este tipo de desenho fomenta os ideais de heróis e suas condutas 
nas brincadeiras infantis, transformando-as e adaptando-as. No nosso entendimento tal fomento vai além, se ampliando também nas diversas esferas do mundo infantil, contemplando, além dos contextos lúdicos, aqueles nos quais o desenho se inscreve, ou seja, a linguagem gráfica visual e para além desta, ramificando-se em outras formas de condutas e expressões comunicacionais das crianças. Como aponta a autora:

Competir, vencer e poder - metas a serem perseguidas por crianças que escapam da tela da TV, dos cards e dos games para fazer parte da vida das crianças de carne e osso, penetrando em seu imaginário e participando de seus ideais (SALGADO, 2005, p.1).

$\mathrm{Na}$ construção destes intertextos as crianças reelaboraram e polifonizam as concepções que adquirem a partir da audiência e assimilação dos desenhos animados. Mesmo que influenciados por estes é importante sublinhar que cada criança trará, no seu traço desenhístico, uma forma singular de perceber e demarcar as particularidades destes a partir de suas próprias circunstâncias sócio-culturais.

Outro aspecto que se põe nesta amostragem demonstra uma relação direta entre as relações de gênero e as escolhas das figuras humanas como condicionante especular que dá forma ao signo gráfico. Meninas desenham meninas, ao passo que meninos desenham meninos. Hipoteticamente, pode-se inferir que o desenho da figura humana se constitui num elemento projetivo sob o qual a criança se percebe corporalmente no espaço do papel e, portanto, neste,a imagem está imantada por construções ideológicas que se cristalizam no ato de desenhar.

Na observância do aspecto sexista apresentado nas produções gráficas adentramos em outra categoria de análise destes desenhos, o que possibilita trazer à baila algumas reflexões postas sob forma de indagações: De que forma as crianças absorvem/aprendem/interiorizam tais relações polarizadoras? Como a escola, através das ferramentas das diversas linguagens colocadas à sua disposição, dentre as quais a linguagem gráfica pode colaborar para desconstruir o antagonismo masculino/feminino, possibilitando que se enxerguem as múltiplas formas de ser menino e ser menina, fazendo com que as fronteiras da divisão de gênero sejam ultrapassadas?

Tais indagações ainda não foram bem examinadas, mas podemos encontrar pesquisas que consideram a influência da variável relações de gênero já na Educação Infantil (AMORIM, 2010), assim como desta no desenho (GOBBI, 1999). É preciso retomar esta questão trazendo aos professores algumas reflexões que impliquem em uma reconfiguração da ação docente com vistas a desconstruir no interior da escola os aspectos polarizadores que reforçam o sexismo.

\section{CONSIDERAÇÕES FINAIS}

Como referendado anteriormente, os desenhos apresentadas foram produzidos por crianças que habitam e estudam no meio rural, fato este que poderia ser destacado, de certa forma nas produções artísticas das crianças. Constatou-se que neste conjunto não existe qualquer elemento que referencie esta realidade o que pode indicar, na pesquisa empírica desenvolvida, a confirmação dahipótese que referencia o meio rural como lócussob o qual não foram estabelecidos laços de pertença e sim o "desenraizamento" do sujeito de sua cultura, condição econômica, valores, dentre outros.

Estas e tantas outras análises têm lugar no contexto dos debates que se sustentam sobre os marcos teóricos da Representação Social e podem contribuir significativamente para práticas e atitudes dos atores sociais na superação dos modelos, condutas e comportamentos hegemônicos que se traduzem nas representações sociais transmitidas por meios visuais ou não.

\section{REFERÊNCIAS}

ALMEIDA, Julia. Entre texto e imagem: título e quadro. ALCEU - v.6 - n.12 - p. 88 a 98 - jan./jun. 2006.

AMORIM, Karen Santos. Minha mãe não deixa eu brincar de carro, porque senão eu viro homem: um estudo sobre as relações de gênero no grupo cinco da Educação Infantil. IV Colóquio Internacional Educação e Contemporaneidade. ISSN 1982-3657. Setembro 2010. 16 p.

ARANHA, Maria Lúcia de Arruda. Filosofando: introdução à Filosofia. São Paulo: Editora Moderna, 1986.

ARBEX, Márcia. As metáforas picturais de René Magritte. Letras (Santa Maria), v. 34, p. 145-160, 2007.

BORTOLETTO, Maíra. Ideologias animadas: a criança e o desenho animado. 2008. Dissertação (Mestrado em Educação) - Faculdade de Educação. UNICAMP. Campinas, SP, 2008

DERDYK, Edith. 0 desenho da figura humana. São Paulo: Scipione, 2003. 2ª edição. 174 p.

GOBBI, Márcia. Lápis vermelho é de mulherzinha: Desenho infantil, relações de gênero e crianças pequenas. Próposições. Campinas, vol.10 no.1(28), p.139-156, mar.1999

GOMES, Luiz Vidal Negreiros. Desenhismo. Santa Maria, Rio Grande do Sul: Editora UFSM, 1996.

KUBRUSLY, Cláudio Araújo. O que é fotografia. São Paulo: Brasiliense, 2003. - Coleção primeiros passos; 82 120p.

MATESCO, Viviane. Corpo, imagem e representação. Rio de Janeiro: Jorge Zahar Ed. 2009.

MENDONÇA, Daniel de. Notas sobre o "efeito de presença" da representação. Rev. Sociol. Polit. [online]. 2004, n. 23, pp. 7987. ISSN 0104-4478. doi: 10.1590/S0104-44782004000200008.

MOSCOVICl, Serge.Representações Sociais: investigação em Psicologia Social.3a edição.Petrópolis, RJ: Vozes, 2003. 404p. 
RANGEL, Mary. A pesquisa de representação social na área de ensino-aprendizagem: elementos do estado da arte. Revista Brasileira de Estudos Pedagógicos, Brasília, v. 79, n.193, set./dez. 1998. p. 72-85.

SALGADO, Raquel Gonçalves. Ser criança e Herói no Jogo e na vida: a infância contemporânea, o brincar e os desenhos animados. 2005. Tese (Doutorado em Psicologia Clínica) Faculdade de Psicologia, PUC-Rio, Rio de Janeiro, 2005.

WECHSLER, Solange Muglia e SCHELINI, Patricia Waltz. Validade do Desenho da Figura Humana para avaliação cognitiva infantil. Aval. psicol., jun. 2002, vol.1, no.1, p.2938. ISSN 1677-0471. 